Full Paper

\title{
Long-term health outcomes in a British cohort of breast, colorectal and prostate cancer survivors: a database study
}

\author{
NF Khan*,', D Mant', L Carpenter', D Forman ${ }^{3}$ and PW Rose' \\ 'Department of Primary Care Health Sciences, University of Oxford, 2nd Floor, 23-38 Hythe Bridge Street, Oxford OXI 2ET, UK; '²Department of Public \\ Health, University of Oxford, Rosemary Rue Building, Old Road Campus, Oxford OX3 7LF, UK; ${ }^{3}$ Cancer Information Section, International Agency for \\ Research on Cancer, 150, Cours Albert Thomas, F-69372 Lyon Cedex 08, France
}

BACKGROUND: The community-based incidence of cancer treatment-related long-term consequences is uncertain. We sought to establish the burden of health outcomes that have been associated with treatment among British long-term cancer survivors. METHODS: We identified 26213 adults from the General Practice Research Database who have survived 5 years or more following breast, colorectal or prostate cancer. Four age-, sex- and general practice-matched non-cancer controls were selected for each survivor. We considered the incidence of treatment-associated health outcomes using Cox proportional hazards models.

RESULTS: Breast cancer survivors had an elevated incidence of heart failure (hazards ratio (HR) 1.95, 95\% confidence interval (Cl) I.27-3.0 I), coronary artery disease (HR I.27, 95\% Cl I.II-I.44), hypothyroidism (HR I.26, 95\% Cl I.02- I.56) and osteoporosis $(\mathrm{HR}$ 1.26, 95\% Cl I.13-1.40). Among colorectal cancer survivors, there was increased incidence of dementia $(\mathrm{HR} 1.68,95 \% \mathrm{Cl}$ I.20-2.35), diabetes (HR I.39, 95\% Cl I. I2- I.72) and osteoporosis (HR I.4I, 95\% Cl I. I5- I.73). Prostate cancer survivors had the highest risk of osteoporosis (HR 2.49, 95\% Cl 1.93-3.22).

CONCLUSIONS: The study confirms the occurrence of increased incidence of chronic illnesses in long-term cancer survivors attributable to underlying lifestyle and/or cancer treatments. Although the absolute risk of the majority of late effects in the cancer survivors cohort is low, identifying prior risk of osteoporosis by bone mineral density scanning for prostate survivors should be considered. There is an urgent need to improve primary care recording of cancer treatment.

British Journal of Cancer (201 I) I 05, S29-S37; doi:I0.1038/bjc.201 I.420 www.bjcancer.com

(c) 201 I Cancer Research UK

Keywords: neoplasms; primary health care; survivors; comorbidity; long-term care

More than $50 \%$ of adults with cancer in the UK will survive for at least 5 years following their initial diagnosis (Cancer Research UK, 2006). Recent improvements in cancer survival are largely due to earlier diagnosis and advancements in treatment. Despite having favourable effects on cancer survival, radiotherapy, hormone treatment and combination chemotherapy regimens can cause long-term organ damage and functional disabilities. These long-term toxicities, or late effects, defined as 'unrecognised toxicities that are absent or subclinical at the end of therapy' can manifest as new diagnoses months to years after the completion of primary cancer treatment (Hewitt et al, 2006). Late effects related to treatment are widely variable and are linked to characteristics of the cancer, the modality and intensity of treatment and the underlying health status of the individual experiencing cancer.

Some late effects are predictable, for example, the effect of radiotherapy treatment on adjacent organs. This may result in the increased incidence of hypothyroidism and heart failure in breast cancer patients (Clarke et al, 2005; Darby et al, 2005; Smith et al, 2008). The effects of hormonal treatments are also predictable; changes in bone physiology and increases in osteoporosis are increasingly found in patients treated with hormone therapy (Chen et al, 2005; Lopez et al, 2005; Shahinian et al, 2005; Saad et al,

\footnotetext{
*Correspondence: Dr NF Khan; E-mail: nada.khan@phc.ox.ac.uk
}

2008; Brown et al, 2010). The late effects of chemotherapy are less easy to predict and are often drug specific. For example, cognitive impairment is a well-recognised late effect of chemotherapy (Hewitt et al, 2006). A conceptual framework of its aetiology proposes interactions between treatment effects on clotting in small blood vessels and endogenous hormones, in addition to chemotherapy mediating depression and fatigue through cytokine involvement leading to cognitive impairment (Heflin et al, 2005). Finally, some associations are difficult to explain with current knowledge. There is a reported association between diabetes mellitus and colorectal cancer: both diseases share common risk factors, but diabetes has also been shown to be a potential independent risk factor of several common cancers including colorectal cancer (Larsson et al, 2005). In addition to the effects of treatment, cancer patients are also at increased risk of developing subsequent disease because of the risk factors that led to the original cancer. Some of these risk factors are modifiable, for example, smoking and alcohol, and a cancer diagnosis may provide motivation for lifestyle change. Other factors, such as genetic mutations and polymorphisms, are currently immutable. A summary of common long-term and late effects of treatments for breast, colorectal and prostate cancer is shown in Table 1.

The prevalence of these late effects in a general population of adult cancer survivors is still uncertain; however, it is likely that with sophisticated and intense treatments long-term effects will become more common (Carver et al, 2007). The complicated 
Table I Examples of potential long-term and late effects of treatment amongst breast, colorectal and prostate cancer survivors

\begin{tabular}{|c|c|c|c|c|c|}
\hline Surgery & \multirow[t]{2}{*}{ Radiotherapy } & \multicolumn{2}{|l|}{ Chemotherapy } & \multicolumn{2}{|l|}{ Hormone therapy } \\
\hline \multicolumn{5}{|l|}{ Breast } & \\
\hline \multirow[t]{18}{*}{ Lymphoedema } & Shoulder stiffening & Anthracyclines & Heart failure & Tamoxifen & Endometrial cancer \\
\hline & Lymphoedema & & Left ventricular (LV) & & Osteopenia \\
\hline & Hypothyroidism & & dysfunction (Hewitt & & Thromboembolic events \\
\hline & Skin telangiectasia & & et al, 2006) & & (Hewitt et al, 2006) \\
\hline & Cardiac damage & Cyclophosphamide & Heart failure & Aromatase inhibitors & Bone loss (Mincey et al, 2006) \\
\hline & Second malignancy & & Pericarditis & & Possible increased risk \\
\hline & Thyroid damage & & Premature menopause & & of artherosclerosis \\
\hline & & & (Hewitt et al, 2006) & & (Senkus and Jassem, 20II) \\
\hline & & Trastuzumab & Heart failure & & \\
\hline & & & LV dysfunction & & \\
\hline & & & (Hewitt et al, 2006) & & \\
\hline & & Bevacizumab & Hypertension & & \\
\hline & & & Thromoembolic events & & \\
\hline & & & Heart failure & & \\
\hline & & & (Choueiri et al, 20l I) & & \\
\hline & & General effects & Weight gain & & \\
\hline & & & Cognitive dysfunction & & \\
\hline & & & (i dir truge el di, zuri) & & \\
\hline \multicolumn{6}{|l|}{ Prostate } \\
\hline \multirow{10}{*}{$\begin{array}{l}\text { Urinary incontinence } \\
\text { Sexual dysfunction }\end{array}$} & Pelvic fibrosis & Rarely used & & LHRH analogues & Coronary artery \\
\hline & Bowel fibrosis & & & & disease (Saigal et al, 2007) \\
\hline & Bladder/bowel & & & & Myocardial infarction \\
\hline & telangiectasia & & & & (Taylor et al, 2009) \\
\hline & & & & & $\begin{array}{l}\text { Osteoporosis (Lopez et al, } \\
\text { 2005; Taylor et al, 2009) }\end{array}$ \\
\hline & & & & & $\begin{array}{l}\text { Mild obesity (Hewitt et al, } \\
\text { 2006) }\end{array}$ \\
\hline & & & & & Sexual dysfunction \\
\hline & & & & & (Schover, 2005) \\
\hline & & & & Bicalutamide & Breast enlargement \\
\hline & & & & & (Hewitt et al, 2006) \\
\hline \multicolumn{6}{|l|}{ Colorectal } \\
\hline \multirow{9}{*}{$\begin{array}{l}\text { Stoma } \\
\text { Bowel and urinary } \\
\text { incontinence } \\
\text { Sexual dysfunction }\end{array}$} & Pelvic necrosis & Bevacizumab & Hypertension & & \\
\hline & Hip osteoporosis & & Thromoembolic events & & \\
\hline & & & Heart failure & & \\
\hline & & & (Hewitt et al, 2006) & & \\
\hline & & 5-Fluorouracil & $\begin{array}{l}\text { Cardiac ischaemia } \\
\text { (Keefe et al, 1993) }\end{array}$ & & \\
\hline & & Oxaliplatin & Peripheral neuropathy & & \\
\hline & & & (Hewitt et al, 2006) & & \\
\hline & & General effects & Cognitive dysfunction & & \\
\hline & & & (Heflin et al, 2005) & & \\
\hline
\end{tabular}

Abbreviation: $\mathrm{LHRH}=$ lutenizing hormone-releasing hormone.

interaction of cancer, cancer treatment and risk factors means that community-based prevalence is difficult to predict. It is important to determine the burden of late effects in cancer survivors in order to provide guidance on long-term monitoring, case finding for disease, health promotion and planning service provision.

The main aim of the research reported here was to assess the size of this problem by documenting the incidence of late effects related to cancer treatment in a population-based cohort of cancer survivors in the UK. Our data, which were derived from comprehensive primary care records, also allowed us to explore the relative incidence of all health problems in cancer survivors compared with a control population.

\section{MATERIALS AND METHODS}

\section{The source of data and participants}

This paper reports a matched cohort analysis of longitudinal primary care records of cancer survivors and controls from the UK General Practice Research Database (GPRD) (Walley and
Mantgani, 1997). The GPRD includes data on individual-level clinical diagnoses, test results, prescriptions, referrals and significant morbidity events in the patients' medical history (MHRA, 2004). All survivors of breast, colorectal and prostate cancer with more than 5 years follow-up post diagnosis were identified from the GPRD and matched to four control patients on the basis of age (within 1 year), gender and primary care practice. These matched groups were followed from the start of a 3-year analysis period beginning on 1 September 2003 and ending on 31 August 2006.

\section{Outcomes}

The main outcomes prespecified in the protocol were the late treatment effects suggested by previous studies, specifically radiotherapy and chemotherapy effects in breast cancer (hypothyroidism, heart failure, coronary artery disease, lymphoedema; Paskett and Stark, 2000; Bradbury et al, 2005; Darby et al, 2005; Carver et al, 2007; Smith et al, 2008) and in prostate and colorectal cancers (erectile dysfunction, incontinence), chemotherapy effects in colorectal cancer (dementia; Heflin et al, 2005) and hormonal effects in breast (osteoporosis) and prostate (osteoporosis and 
coronary artery disease; Chen et al, 2005; Shahinian et al, 2005; Saad et al, 2008; Taylor et al, 2009). We also prespecified diabetes mellitus as an outcome because of its reported association with colorectal cancer (Larsson et al, 2005; Keating et al, 2006). We also considered long-term effects of treatment specific to each cancer, including lymphoedema (breast cancer), early menopause (breast cancer), non-infectious diarrhoea or constipation (colorectal cancer), erectile dysfunction (male colorectal and prostate cancer) and urinary incontinence (colorectal and prostate cancer). We focussed on outcomes that we could investigate within the GPRD by identifying incident events through Read or OXMIS codes for the clinical diagnosis, with the exception of osteoporosis - for which patients prescribed a bisphosphonate were included even if they did not have a clinical code for osteoporosis or osteoporotic fracture - and erectile dysfunction - for which we included new prescriptions for sildenafil (Viagra, Pfizer, NY, United States), apomorphone hydrochloride, vardenafil (Levitra, Bayer Healthcare Pharmaceuticals, New Haven, USA), alprostadil (an injectable treatment) and tadalafil (Cialis, Lilly, USA). Early menopause was defined as a clinical code for menopause or early menopause in the patient's electronic medical record before the age of 48 years. Clinical code lists are available on request. Only new diagnoses were included (i.e., diagnoses that were not present in the medical record before the cancer diagnosis) in any analyses of disease incidence.

\section{Statistical analyses}

We calculated the incidence rate for each outcome based on the number of events and cumulative person-years for each group of cancer survivors and controls within the analysis period. We used multivariate Cox proportional hazard models, stratifying for the matched groups, to compute hazard ratios (HRs) and $95 \%$ confidence intervals (95\% CIs). This method allowed us to compare the incidence rates for matched groups of cancer survivors and controls. We only considered incidence of new diagnoses, and therefore excluded any patients with a previous diagnosis of the condition of interest before the start of the analysis period. To formally test the proportional hazards model assumption that the HR is proportional over time, we conducted post-estimation tests of the correlations between Schoenfeld residuals from each multivariate model and time (Cleves et al, 2006). In addition to incidence within the analysis period, we also report total prevalence from date of cancer diagnosis in the survivors and from date of matched survivor in the control population. All analyses were carried out using the Stata MP statistical software, version 10.1 (StataCorp LP, College Station, TX, USA).

\section{Explanatory variables}

To reduce confounding, we adjusted for smoking status and BMI in case-control comparisons of the incidence of heart failure, dementia, coronary artery disease, osteoporosis, diabetes and erectile dysfunction (Kanis et al, 2005). Recording of smoking status is high in the GPRD; however, data on former smoking status are lower than expected (Lewis et al, 2004). Smokers may be alternatively coded as ex, former or current smokers. Therefore, we classified individuals as ever smokers or never smokers. In addition, each patient was assigned a summary comorbidity score based on the Charlson index. This weighted and additive comorbidity score consists of 17 diagnostic categories and accounts for both the number and severity of comorbidity to provide a summary of disease burden for individual patients (Charlson et al, 1987). It has been adapted for use within the GPRD (Khan et al, 2010b).

Data on patient characteristics such as BMI and smoking status were not complete within the GPRD; however, coverage was high (Table 2). We compared three different approaches to dealing with the missing data in multivariate Cox proportional hazard models: multiple imputation, complete case analysis and use of a 'missing' category. As results for all three approaches were similar, we report the results from the complete case analysis.

\section{RESULTS}

\section{Patient characteristics}

Table 2 reports the age, gender, time since diagnosis and comorbidity score of 26213 long-term survivors of breast, colorectal and prostate cancer and a matched control population of 104486 . The cohort was fairly elderly, and a high proportion of the population had at least one comorbid disease. It also shows that two of the most important confounding factors (smoking and BMI) were in fact very similar in prevalence among all survivors and controls, despite previous research showing a positive association between obesity and risk of cancer (Bianchini and Vainio, 2002).

\section{Breast cancer survivors}

Incidence rates and risk of new diagnoses related to late effects of treatment among breast cancer survivors and controls are shown in Table 3. Long-term survivors of breast cancer had an incident rate for heart failure of 5.73 per 1000 person-years compared with 4.40 in controls. This excess persisted in matched, multivariate models (adjusted HR 1.95, 95\% CI 1.27-3.01). In addition, breast cancer survivors had a significantly elevated incidence of osteoporosis compared with controls (adjusted HR 1.26, 95\% CI $1.13-1.40)$. We included use of bisphosphonates as indicative of a diagnosis of osteoporosis; however, some breast cancer survivors may be receiving prophylactic bisphosphonate treatment to prevent osteoporosis. To assess whether our case definition was affecting these results, we conducted a sensitivity analysis after excluding women receiving bisphosphonates from the analysis. The risk of developing a new diagnosis of osteoporosis was broadly similar (adjusted HR 1.38, 95\% CI 1.19-1.60). A total of 260 breast cancer survivors were clinically coded with lymphoedema, which corresponded to an incidence rate of 6.73 per 1000 person-years (95\% CI 5.95-7.59) and a substantially elevated rate of disease compared with controls (HR 18.12, 95\% CI 13.6-24.1). There was evidence for a slight increase in the risk of early menopause among breast cancer survivors (adjusted HR 1.25, 95\% CI 1.06-1.48).

Coronary artery disease and hypothyroidism crude incidence rates were similar in breast cancer survivors and controls. After accounting for matched groups and additional covariates, there was evidence for an increased rate of coronary artery disease (adjusted HR 1.27, 95\% CI 1.11-1.44) and a marginal increase in the risk of hypothyroidism (adjusted HR 1.26, 95\% CI 1.02-1.56) in breast cancer survivors. Coronary artery disease can affect heart muscle function, and ultimately is a leading cause of heart failure; however, because we have treated each outcome separately in the analysis, this causal effect is unlikely to affect the estimates for heart failure. Nevertheless, we compared the risk of heart failure among breast cancer survivors who only had a clinical code for heart failure (137 new diagnoses, HR 3.44, 95\% CI 2.86-4.02) and among breast cancer survivors with a clinical code for CAD and heart failure (91 new diagnoses, HR 2.29, 95\% CI 1.82-2.76).

\section{Colorectal cancer survivors}

Incidence rates of new diagnoses associated with surviving colorectal cancer are shown in Table 4 . There was evidence for an increase in the incidence of dementia in colorectal cancer survivors compared with controls (adjusted HR 1.68, 95\% CI $1.20-2.35)$ after adjusting for BMI and Charlson score. In addition, there was an increase of new diagnoses of diabetes among colorectal cancer survivors, and this risk remained after adjusting 
Table 2 Characteristics of cancer survivors and matched controls (four patients of the same age and gender from the same primary care practice without a diagnosis of cancer) by cancer type

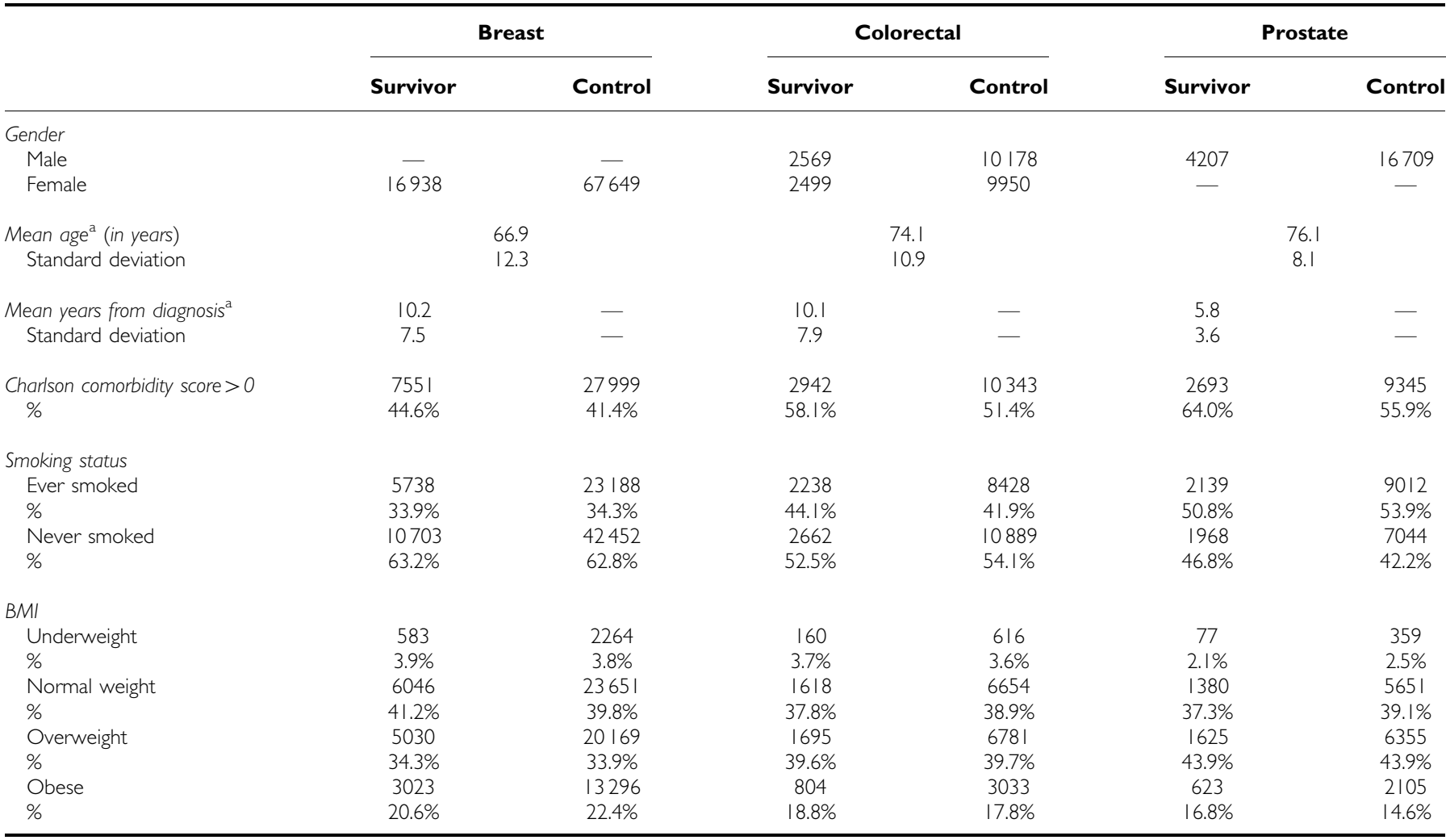

aThe date used to calculate years from cancer diagnosis was I September 2003, and the year used to calculate age was 2003

for BMI and smoking (adjusted HR 1.39, 95\% 1.12-1.72). Colorectal cancer survivors also had a significantly higher incidence of osteoporosis (adjusted HR 1.41, 95\% CI 1.15-1.73). Incidence, prevalence and risk of long-term effects including erectile dysfunction (adjusted HR 1.39, 95\% CI 1.08-1.77), urinary incontinence (HR 1.79, 95\% CI $1.40-2.30$ ) and bowel dysfunction (HR 1.43, 95\% CI 1.26-1.63) were significantly elevated in colorectal cancer survivors post diagnosis.

\section{Prostate cancer survivors}

Table 5 shows the incidence and risk of new diagnoses among prostate cancer survivors and controls. Prostate cancer survivors had a large increase in the rate of osteoporosis compared with matched controls (adjusted HR 2.49, 95\% CI 1.93-3.22). Similar to the breast cancer analysis, we excluded men receiving bisphosphonates from the case definition for osteoporosis. The results were broadly similar (adjusted HR is $1.92,95 \%$ CI $1.35-2.72$ ). There were no differences in the incidence rate of heart failure or coronary artery disease between prostate cancer survivors and controls. Although the multivariate analysis showed no difference in the risk of developing erectile dysfunction among prostate cancer survivors, the incidence rate of erectile dysfunction was significantly higher among the prostate cancer group (23.5 new diagnoses per 1000 person-years, 95\% CI 20.2-27.2). Prostate cancer survivors were significantly more likely to experience urinary incontinence, with a significantly higher total prevalence (Table 6) and long-term risk of new events (HR 3.20, 95\% CI 2.45-4.16).

\section{Total prevalence}

In addition to new diagnoses during the analysis period, we also considered total prevalence of the long-term effects, including urinary incontinence, erectile dysfunction and bowel dysfunction (Table 6). The number of cancer survivors with a clinical record for these long-term effects significantly increased compared with the control population, and for the most part corresponded to the relative risks reported in the proportional hazards models with the exception of erectile dysfunction, which was recorded in almost twice as many prostate cancer survivors as controls.

\section{DISCUSSION}

\section{Statement of principal findings}

This large population-based matched cohort study has described the incidence and risk of new diagnoses related to late effects of treatment in long-term survivors of breast, colorectal and prostate cancer. We have confirmed previously reported associations between breast cancer and heart failure, coronary artery disease and hypothyroidism, and the increased risk of osteoporosis in all three cancers. We did not confirm the increase of coronary artery disease in prostate cancer; however, this analysis did show an association between colorectal cancer and diabetes mellitus, with an increased incidence of almost four new cases of diabetes per 1000 person-years. The incidence rate for osteoporosis was comparable between all cancer groups. Despite these associations, the absolute rise in incidence is very modest in this general population, with the exception of osteoporosis and urinary incontinence among prostate cancer survivors.

\section{Comparison with other research}

This is the first UK-based study to report the incidence and risk of new diagnoses related to late effects of treatment in an unselected population of cancer survivors. The study confirms most of the 
Table 3 Incidence of new diagnoses related to treatment amongst breast cancer survivors

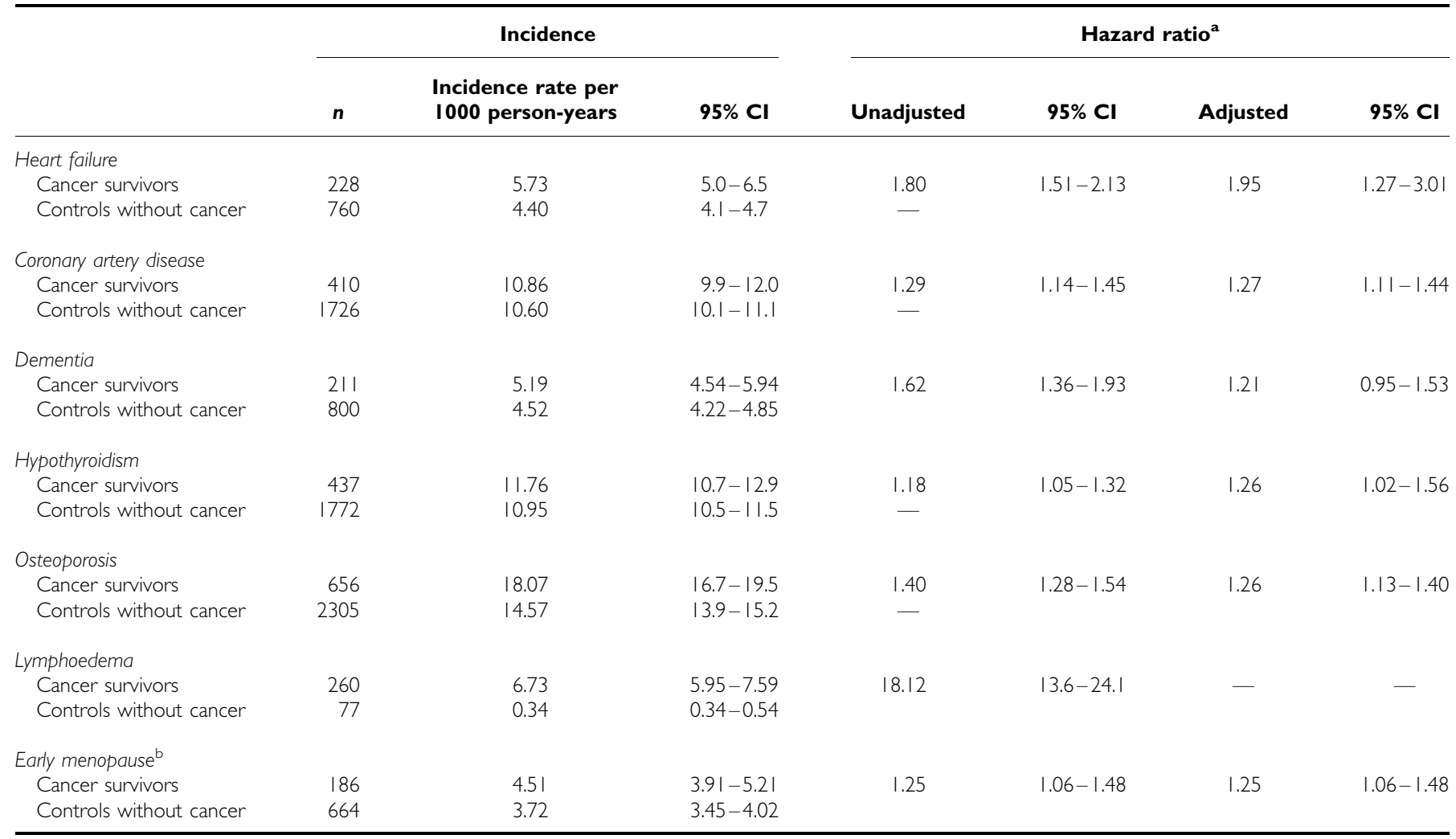

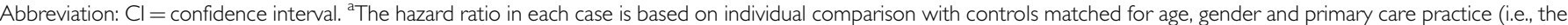
comparison for patients treated with radiotherapy is with controls individually matched to patients receiving radiotherapy rather than all controls); the adjusted hazard ratio takes account of the potential confounding effect of smoking and BMI (except for hypothyroidism which is adjusted for BMI and history of hormone therapy only, and early menopause which is adjusted for smoking only). ${ }^{b}$ Defined as menopause before the age of 48 years.

Table 4 Incidence of new diagnoses related to treatment among colorectal cancer survivors

\begin{tabular}{|c|c|c|c|c|c|c|c|}
\hline & \multicolumn{3}{|c|}{ Incidence } & \multicolumn{4}{|c|}{ Hazard ratio ${ }^{a}$} \\
\hline & $n$ & $\begin{array}{l}\text { Incidence rate per } \\
1000 \text { person-years }\end{array}$ & $95 \% \mathrm{Cl}$ & Unadjusted & $95 \% \mathrm{Cl}$ & Adjusted & $95 \% \mathrm{Cl}$ \\
\hline \multicolumn{8}{|l|}{ Dementia } \\
\hline Cancer survivors & 116 & 10.08 & $8.4-12.1$ & 2.10 & $1.65-2.68$ & 1.68 & $1.20-2.35$ \\
\hline Controls without cancer & 356 & 7.02 & $6.3-7.8$ & - & & & \\
\hline \multicolumn{8}{|l|}{ Osteoporosis } \\
\hline Controls without cancer & 597 & 12.86 & $11.9-13.9$ & - & & & \\
\hline \multicolumn{8}{|l|}{ Diabetes } \\
\hline Cancer survivors & 176 & 17.01 & $14.7-19.7$ & 1.40 & $1.15-1.70$ & 1.39 & $1.12-1.72$ \\
\hline Controls without cancer & 616 & 13.21 & $12.2-14.3$ & - & & & \\
\hline \multicolumn{8}{|l|}{ Erectile dysfunction } \\
\hline \multicolumn{8}{|l|}{ Urinary incontinence } \\
\hline Controls without cancer & 853 & 12.09 & $11.3-12.9$ & & & & \\
\hline \multicolumn{8}{|l|}{ Diarrhoea or constipation } \\
\hline Cancer survivors & 441 & 67.99 & $61.9-74.6$ & 1.43 & $1.26-1.63$ & & \\
\hline Controls without cancer & 1939 & 51.68 & $49.4-54.0$ & & & & \\
\hline
\end{tabular}

Abbreviation: $\mathrm{Cl}=$ confidence interval. ${ }^{\mathrm{a}}$ The hazard ratio in each case is based on individual comparison with controls matched for age, gender and primary care practice; the adjusted hazard ratio takes account of the potential confounding effect of comorbidity, BMI (and for osteoporosis and erectile dysfunction also for smoking). 
Table 5 Incidence of new diagnoses related to treatment amongst prostate cancer survivors

\begin{tabular}{|c|c|c|c|c|c|c|c|}
\hline & \multicolumn{3}{|c|}{ Incidence } & \multicolumn{4}{|c|}{ Hazard ratio ${ }^{a}$} \\
\hline & $n$ & $\begin{array}{l}\text { Incidence rate per } \\
1000 \text { person-years }\end{array}$ & $95 \% \mathrm{Cl}$ & Unadjusted & $95 \% \mathrm{Cl}$ & Adjusted & $95 \% \mathrm{Cl}$ \\
\hline \multicolumn{8}{|l|}{ Heart failure } \\
\hline Cancer survivors & 129 & 17.1 & | $4.4-20.3$ & 1.66 & $1.32-2.10$ & 1.23 & $0.91-1.66$ \\
\hline Controls without cancer & 486 & 13.8 & $12.6-15.1$ & - & & & \\
\hline \multicolumn{8}{|l|}{ Coronary artery disease } \\
\hline Controls without cancer & 863 & 29.15 & $27.3-31.2$ & - & & & \\
\hline \multicolumn{8}{|l|}{ Osteoporosis } \\
\hline Cancer survivors & 120 & 15.38 & $12.9-18.4$ & 2.39 & $1.89-3.00$ & 2.49 & $1.93-3.22$ \\
\hline Controls without cancer & 292 & 7.98 & $7.1-8.9$ & - & & & \\
\hline \multicolumn{8}{|l|}{ Erectile dysfunction } \\
\hline Cancer survivors & 315 & 20.43 & $18.3-22.8$ & 3.20 & $2.45-4.16$ & & \\
\hline Controls without cancer & 677 & 12.45 & $11.5-13.4$ & & & & \\
\hline
\end{tabular}

Abbreviation: $\mathrm{Cl}=$ confidence interval. ${ }^{\text {aTh }}$ The hazard ratio in each case is based on individual comparison with controls matched for age, gender and primary care practice (i.e. the comparison for patients treated with radiotherapy is with controls individually matched to patients receiving radiotherapy rather than all controls); the adjusted hazard ratio takes account of the potential confounding effect of comorbidity, smoking and BMI.

Table 6 Total prevalence of long-term effects in cancer survivors and controls

\begin{tabular}{|c|c|c|c|}
\hline & $\begin{array}{l}\text { Number } \\
\text { of events }\end{array}$ & $\begin{array}{c}\text { No } \\
\text { event }\end{array}$ & $\begin{array}{c}\text { Total } \\
\text { patients }\end{array}$ \\
\hline \multicolumn{4}{|c|}{ Urinary incontinence } \\
\hline \multicolumn{4}{|l|}{ Prostate } \\
\hline Survivor & $411(9.8 \%)^{\mathrm{a}}$ & 3796 (90.2\%) & 4207 \\
\hline Control & $525(3.1 \%)$ & 16184 (96.9\%) & 16709 \\
\hline \multicolumn{4}{|l|}{ Colorectal } \\
\hline Survivor & $324(6.4 \%)^{\mathrm{a}}$ & 4744 (93.6\%) & 5068 \\
\hline Control & $1022(5.1 \%)$ & $19106(94.9 \%)$ & 20128 \\
\hline \multicolumn{4}{|c|}{ Erectile dysfunction } \\
\hline \multicolumn{4}{|l|}{ Prostate } \\
\hline Survivor & $662(15.7 \%)^{\mathrm{a}}$ & 3545 (84.3\%) & 4207 \\
\hline Control & 1394 (8.3\%) & 15315 (91.7\%) & 16709 \\
\hline \multicolumn{4}{|c|}{ Colorectal (men only) } \\
\hline Survivor & $344(13.4 \%)^{a}$ & 2225 (86.6\%) & 2569 \\
\hline Control & $931(9.2 \%)$ & 9247 (90.8\%) & 10178 \\
\hline \multicolumn{4}{|c|}{ Diarrhoea or constipation } \\
\hline \multicolumn{4}{|l|}{ Colorectal } \\
\hline Survivor & $2300(45.4 \%)^{\mathrm{a}}$ & 2768 (54.6\%) & 5068 \\
\hline Control & 5792 (28.8\%) & $14336(71.2 \%)$ & 20128 \\
\hline
\end{tabular}

asignificant at $P<0.0001$ in Pearson's $X^{2}$-comparisons.

reported associations between treatment and outcomes drawn from cross-sectional studies and specialist databases. The risk of heart failure, hypothyroidism and osteoporosis among breast cancer survivors in this cohort was similar to previously reported research (Mincey et al, 2006; Pinder et al, 2007; Smith et al, 2008). However, rates of osteoporosis among prostate cancer survivors in this cohort were substantially higher compared with the results from a meta-analysis assessing the risk of androgen deprivation therapy-related osteoporosis (Taylor et al, 2009). We did not identify any non-reported outcomes from this study. Low-level incontinence can develop in some patients many years after radical prostatectomy. Previous research on the incidence of pelvic late effects has documented a substantial increase in the risk of bowel and urinary incontinence, which was mirrored in this cohort where the incidence of long-term effects such as urinary incontinence, erectile dysfunction and bowel dysfunction was substantially higher among the cancer survivors in this population (Farnell et al, 2010; Henson et al, 2011). These may affect cancer survivors closer to diagnosis; however, we did not have longitudinal followup data on this cohort before 2 years post diagnosis (Chen et al, 2009).

\section{Strengths and limitations}

This analysis uses data from a large, representative database, and quantified new diagnoses in a community-based group of cancer survivors with a robust comparison population. Although large data repositories such as the GPRD offer the opportunity to access information on a large number of patients, there are several limitations inherent to conducting research in a data set that has not been collected primarily for research purposes. The main drawback of this observational research is that it is not possible to explore the relationships between specific treatments and new diagnoses. A lack of detailed treatment information from the GPRD prevented analysis of treatment effects among the entire cohort. We attempted to gain additional treatment data by linking this GPRD data set with National Cancer Intelligence Network (NCIN); however, historical treatment data have not been consistently recorded across the different national cancer registries. A summary of treatment data that was available for this study is shown in Appendix. There is a strong need for improvements in capturing cancer treatment at cancer registries, and more importantly cancer treatment data need to be incorporated into patient electronic medical records in primary care. Read coding of radiotherapy, chemotherapy and surgery is weak in primary care, which needs to improve before general practitioners (GPs) can identify individual cancer treatment histories and assess risk for late effects among long-term cancer survivors. In addition, because 
individual-level data are limited, we have only taken a small proportion of potentially confounding baseline patient characteristics into account.

The results need to be interpreted with caution, as the mechanisms underlying these new diagnoses have not been fully elucidated, disease definitions are not standardised in the GPRD and incident diseases may result from shared risk factors with the initial cancer (Wefel and Meyers, 2005). Although conducting a comparison between cancer survivors and a control population minimises bias due to misclassification or failure to record clinical data, it is possible that the raised risks of disease are partly due to increased follow-up and clinical contact among the cancer survivors group. In addition, we have conducted numerous statistical tests, but have not adjusted for multiple comparisons.

Case definition is an important issue to consider when using administrative databases for research purposes (Khan et al, 2010a). Previous validation studies of the GPRD have suggested that prescribing data can be used to capture additional cases when the prescribed drug is specific to the diagnosis of interest (Hansell et al, 1999). Accordingly, we included bisphosphonates in the case definition for osteoporosis among the cancer survivors and control population, which was supported by sensitivity analyses. Use of prophylactic bisphosphonates for prevention of osteoporosis is not currently recommended among cancer survivors receiving aromatase inhibitors; however, it is possible that this may occur in practice. It is also possible that prostate cancer survivors receiving bisphosphonates as treatment for skeletal metastases were wrongly attributed as osteoporotic. It is a potential limitation of these analyses that it has not been possible to specifically identify those patients with secondary disease; however, only 14 of the 120 prostate cancer survivors who were identified as osteoporotic solely on the basis of a new prescription of a bisphosphonate had a PSA level suggestive of secondary disease (defined as at least one PSA reading over $50 \mathrm{ng} \mathrm{ml}^{-1}$ ), which suggests that misclassification bias is minimal in this instance. Furthermore, results of a sensitivity analysis excluding those patients receiving bisphosphonates show broadly similar relative results for risk of osteoporosis among cancer survivors compared with matched controls.

\section{Implications of the study}

Although this study has shown that long-term cancer survivors are a population at risk, the absolute increase in disease burden is small apart from the risk of osteoporosis. Most cancer survivors readjust to their disease and do not have long-term physical or psychological sequelae. These findings support the approach of the UK National Cancer Survivors Initiative to develop risk stratification tools to manage cancer survivors post treatment (National Cancer Survivorship (NSCI) Research Workstream, 2010). Most of these patients will be cared for in primary care, and GPs will need an awareness of the increased risks in individual patients. Our findings certainly suggest a substantially increased risk of osteoporosis among prostate cancer survivors, and adequate surveillance systems are required to manage this risk. Guidelines developed by the National Institute for Health and Clinical Excellence recommend baseline dual energy X-ray absorptiometry scans to women with breast cancer; however, no current guidelines exist for the management of bone loss among prostate cancer survivors (National Collaborating Centre for Cancer, 2009). General practitioners will also need to pay special attention to the presence of risk factors in this population that may have led to the original cancer diagnosis, as well as managing long-term treatment effects.

Although large, prospective cohort studies have described late effects among childhood cancer survivors (Oeffinger et al, 2006; Reulen et al, 2007), there is a strong need for similar work among survivors of adult cancer. In order to better elucidate the relationships between treatment and late effects, future research needs to involve detailed and individual-level treatment data; this will allow an assessment of risk stratified by treatment. This may involve further research using existing databases, as recording of treatment improves within cancer registries and primary care, or long-term follow-up of participants of treatment clinical trials where detailed information on treatment and individual-level patient characteristics will have been collected at baseline.

\section{Conclusion}

This research has confirmed the increased incidence of previously reported late effects of treatment in long-term survivors of cancer in an unselected population. Although the absolute increase of most late effects is small, clinicians will need an awareness of these risks.

\section{ACKNOWLEDGEMENTS}

This article is sponsored by Macmillan Cancer Support through its Research Capacity Development Programme and by Cancer Research UK grant number C23140/A8854. We thank Jane Maher for her helpful comments on the manuscript.

\section{Author contributions}

PWR, NFK and DM were responsible for the study design. NFK, DM, LC and PWR planned the data analysis, and NFK conducted all statistical analyses, prepared tables and drafted the manuscript. DF assisted with NCIN data provision and interpretation of treatment data. PWR is the principal investigator of the study. All authors revised and commented on the manuscript and approved the final draft.

\section{Ethics approval}

The GPRD Group has obtained ethical approval for all observational research using GPRD data. This study has been approved by the Independent Scientific Advisory Committee (ISAC) of the GPRD (ISAC protocol No. 06_051R).

\section{REFERENCES}

Bianchini F, Vainio H (2002) Overweight, obesity and cancer risk. Lancet Oncol 3(9): $565-574$

Bradbury BD, Lash TL, Kaye JA, Jick SS (2005) Tamoxifen-treated breast carcinoma patients and the risk of acute myocardial infarction and newly-diagnosed angina. Cancer 103(6): 1114-1121

Brown JE, Sherriff JM, James ND (2010) Osteoporosis in patients with prostate cancer on long-term androgen deprivation therapy: an increasing, but under-recognized problem. Br J Urol 105(8): 1042 - 1043

Cancer Research UK (2006) CancerStats. Survival - UK. http://info. cancerresearchuk.org/cancerstats/survival/ (accessed 3 September 2009)
Carver JR, Shapiro CL, Ng A, Jacobs L, Schwartz C, Virgo KS, Hagerty KL, Somerfield MR, Vaughn DJ (2007) American Society of Clinical Oncology clinical evidence review on the ongoing care of adult cancer survivors: cardiac and pulmonary late effects. J Clin Oncol 25(25): $3991-4008$

Charlson ME, Pompei P, Ales KL, MacKenzie CR (1987) A new method of classifying prognostic comorbidity in longitudinal studies: development and validation. J Chronic Dis 40(5): 373-383

Chen RC, Clark JA, Talcott JA (2009) Individualizing quality-of-life outcomes reporting: how localized prostate cancer treatments affect 
patients with different levels of baseline urinary, bowel, and sexual function. J Clin Oncol 27(24): 3916-3922

Chen Z, Maricic M, Pettinger M, Ritenbaugh C, Lopez AM, Barad DH, Gass M, Leboff MS, Bassford TL (2005) Osteoporosis and rate of bone loss among postmenopausal survivors of breast cancer. Cancer 104(7): $1520-1530$

Choueiri TK, Mayer EL, Je Y, Rosenberg JE, Nguyen PL, Azzi GR, Bellmunt J, Burstein HJ, Schutz FA (2011) Congestive heart failure risk in patients with breast cancer treated with bevacizumab. J Clin Oncol 29(6): $632-638$

Clarke M, Collins R, Darby S, Davies C, Elphinstone P, Evans E, Godwin J, Gray R, Hicks C, James S, MacKinnon E, McGale P, McHugh T, Peto R, Taylor C, Wang Y (2005) Effects of radiotherapy and of differences in the extent of surgery for early breast cancer on local recurrence and 15-year survival: an overview of the randomised trials. Lancet 366(9503): 2087-2106

Cleves MA, Gould WG, Gutierrez R (2006) An Introduction to Survival Analysis using Stata. Stata Press: College Station, Texas

Darby SC, McGale P, Taylor CW, Peto R (2005) Long-term mortality from heart disease and lung cancer after radiotherapy for early breast cancer: prospective cohort study of about 300,000 women in US SEER cancer registries. Lancet Oncol 6(8): $557-565$

Farnell DJ, Mandall P, Anandadas C, Routledge J, Burns MP, Logue JP, Wylie JP, Swindell R, Livsey J, West CM, Davidson SE (2010) Development of a patient-reported questionnaire for collecting toxicity data following prostate brachytherapy. Radiother Oncol 97(1): $136-142$

Hansell A, Hollowell J, Nichols T, McNiece R, Strachan D (1999) Use of the General Practice Research Database (GPRD) for respiratory epidemiology: a comparison with the 4th Morbidity Survey in General Practice (MSGP4). Thorax 54(5): 413-419

Heflin LH, Meyerowitz BE, Hall P, Lichtenstein P, Johansson B, Pedersen NL, Gatz M (2005) Cancer as a risk factor for long-term cognitive deficits and dementia. J Natl Cancer Inst 97(11): 854-856

Henson CC, Andreyev HJ, Symonds RP, Peel D, Swindell R, Davidson SE (2011) Late-onset bowel dysfunction after pelvic radiotherapy: a National survey of current practice and opinions of clinical oncologists. Clin Oncol (R Coll Radiol) 23(8): 552-557

Hewitt M, Greenfield S, Stovall E (eds) (2006) From Cancer Patient to Cancer Survivor: Lost in Transition. The National Academies Press: Washington DC

Kanis JA, Johnell O, Oden A, Johansson H, De LC, Eisman JA, Fujiwara S, Kroger H, McCloskey EV, Mellstrom D, Melton LJ, Pols H, Reeve J, Silman A, Tenenhouse A (2005) Smoking and fracture risk: a metaanalysis. Osteoporos Int 16(2): 155-162

Keating NL, O'Malley AJ, Smith MR (2006) Diabetes and cardiovascular disease during androgen deprivation therapy for prostate cancer. J Clin Oncol 24(27): 4448-4456

Keefe DL, Roistacher N, Pierri MK (1993) Clinical cardiotoxicity of 5-fluorouracil. J Clin Pharmacol 33(11): 1060-1070

Khan NF, Harrison SE, Rose PW (2010a) Validity of diagnostic coding within the General Practice Research Database: a systematic review. Br J Gen Pract 60(572): e128-e136

Khan NF, Perera R, Harper S, Rose PW (2010b) Adaptation and validation of the Charlson Index for Read/OXMIS coded database. BMC Fam Prac 11: 1

Larsson SC, Orsini N, Wolk A (2005) Diabetes mellitus and risk of colorectal cancer: a meta-analysis. J Natl Cancer Inst 97(22): $1679-1687$

Lewis JD, Brensinger C, Lewis JD, Brensinger C (2004) Agreement between GPRD smoking data: a survey of general practitioners and a populationbased survey. Pharmacoepidemiol Drug Saf 13(7): 437 - 441
Lopez AM, Pena MA, Hernandez R, Val F, Martin B, Riancho JA (2005) Fracture risk in patients with prostate cancer on androgen deprivation therapy. Osteoporos Int 16(6): 707-711

MHRA (2004) GPRD Recording Guidelines for Vision Users. Crown Publishing: London

Mincey BA, Duh MS, Thomas SK, Moyneur E, Marynchencko M, Boyce SP, Mallett D, Perez EA (2006) Risk of cancer treatment-associated bone loss and fractures among women with breast cancer receiving aromatase inhibitors. Clin Breast Cancer 7(2): 127-132

National Cancer Survivorship (NSCI) Research Workstream (2010) Priorities for research on cancer survivorship. http://www.ncsi.org.uk/ research/

National Collaborating Centre for Cancer (2009) CG80 Early and Locally Advanced Breast Cancer: Full Guideline. National Collaborating Centre for Cancer: Cardiff

Oeffinger KC, Mertens AC, Sklar CA, Kawashima T, Hudson MM, Meadows AT, Friedman DL, Marina N, Hobbie W, Kadan-Lottic NS, Schwartz CL, Leisenring W, Robison LL (2006) Chronic health conditions in adult survivor of childhood cancer. N Engl J Med 355(15): $1572-1582$

Partridge AH, Burstein HJ, Winer EP (2001) Side effects of chemotherapy and combined chemohormonal therapy in women with early-stage breast cancer. J Natl Cancer Inst Monogr 30: 135-142

Paskett ED, Stark N (2000) Lymphedema: knowledge, treatment, and impact among breast cancer survivors. Breast J 6(6): $373-378$

Pinder MC, Duan Z, Goodwin JS, Hortobagyi GN, Giordano SH (2007) Congestive heart failure in older women treated with adjuvant anthracycline chemotherapy for breast cancer. J Clin Oncol 25(25): $3808-3815$

Reulen RC, Winter DL, Lancashire ER, Zeegers MP, Jenney ME, Walters SJ, Jenkinson C, Hawkins MM (2007) Health-status of adult survivors of childhood cancer: a large-scale population-based study from the British Childhood Cancer Survivor Study. Int J Cancer 121(3): 633-640

Saad F, Adachi JD, Brown JP, Canning LA, Gelmon KA, Josse RG, Pritchard KI (2008) Cancer treatment-induced bone loss in breast and prostate cancer. J Clin Oncol 26(33): 5465-5476

Saigal CS, Gore JL, Krupski TL, Hanley J, Schonlau M, Litwin MS (2007) Androgen deprivation therapy increases cardiovascular morbidity in men with prostate cancer. Cancer 110(7): 1493-1500

Schover LR (2005) Sexuality and fertility after cancer. Hematology Am Soc Hematol Educ Program 1: 523-527

Senkus E, Jassem J (2011) Cardiovascular effects of systemic cancer treatment. Cancer Treat Rev 37(4): 300-311

Shahinian VB, Kuo YF, Freeman JL, Goodwin JS (2005) Risk of fracture after androgen deprivation for prostate cancer. N Engl J Med 352(2): $154-164$

Smith GL, Smith BD, Giordano SH, Shih YC, Woodward WA, Strom EA, Perkins GH, Tereffe W, Yu TK, Buchholz TA (2008) Risk of hypothyroidism in older breast cancer patients treated with radiation. Cancer 112(6): $1371-1379$

Taylor LG, Canfield SE, Du XL (2009) Review of major adverse effects of androgen-deprivation therapy in men with prostate cancer. Cancer 115(11): $2388-2399$

Walley T, Mantgani A (1997) The UK general practice research database. Lancet 350(9084): 1097-1099

Wefel JS, Meyers CA (2005) Cancer as a risk factor for dementia: a house built on shifting sand. J Natl Cancer Inst 97(11): 788-789

(c) (i) (2) This work is licensed under the Creative Commons

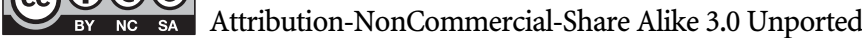
License. To view a copy of this license, visit http://creativecommons. org/licenses/by-nc-sa/3.0/ 


\section{Appendix}

Treatment data available in GPRD-NCIN-linked database

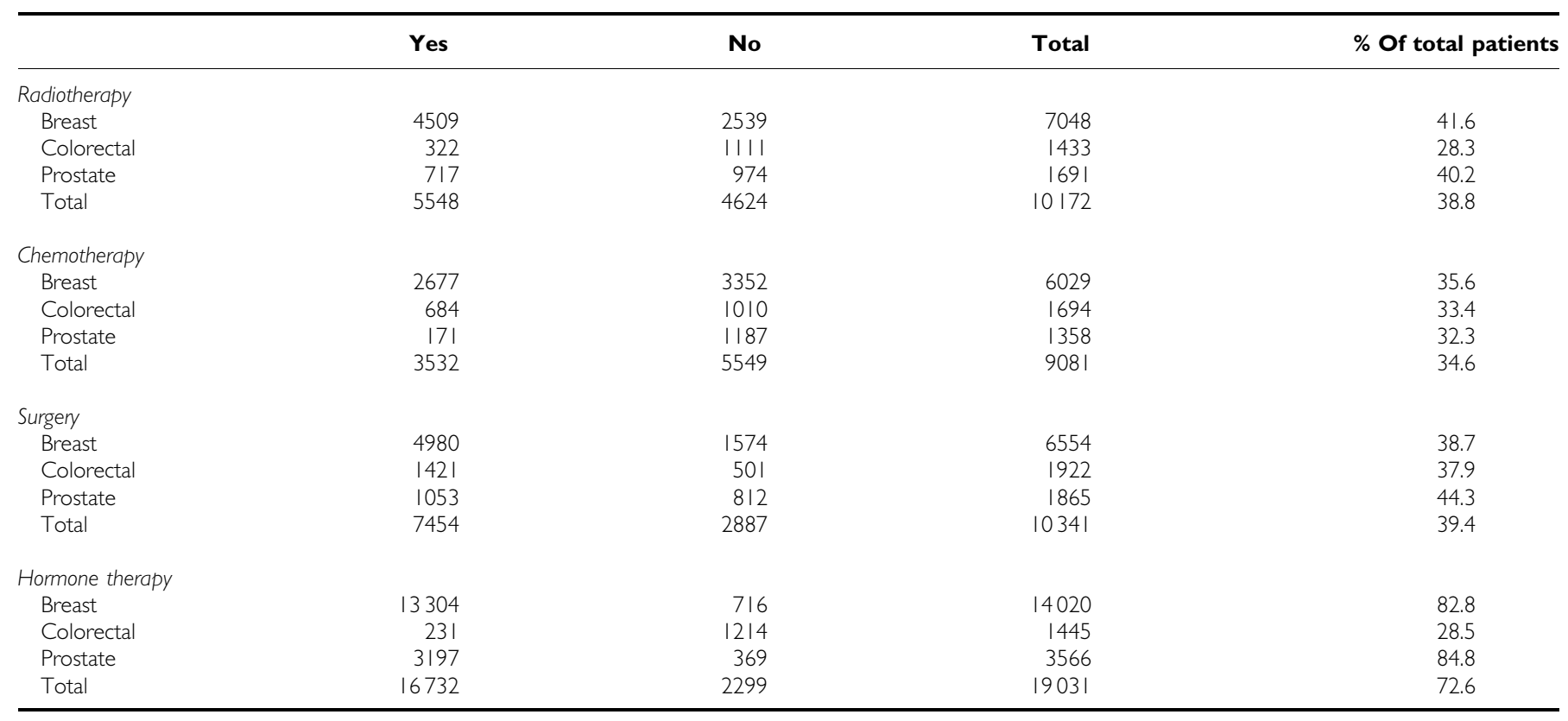

